\title{
Perspectivas institucionales y prácticas de las cooperativas en Cuba
}

\author{
C. Orisel Hernández Aguilar ${ }^{1}$ \\ Universidad de Pinar del Río, Cuba
}

doi: http://dx.doi.org/10.18543/dec-14-2019pp143-164

Recibido: 08-11-2019

Aceptado: 22-11-2019

Sumario: I. Introducción II. Las cooperativas como protagonistas del desarrollo local III. Informatización de las cooperativas como parte de la sociedad cubana. IV. Retos para las cooperativas ante los nuevos escenarios del comercio V. Proyección de las cooperativas ante la expansión de la propiedad mixta VI. Necesidad de perfeccionamiento de la asesoría jurídica a las cooperativas VII. A modo de conclusiones.

Resumen: El presente trabajo se propone analizar algunas de las perspectivas institucionales y prácticas que se abren para las cooperativas en Cuba en el actual escenario constitucional y legal. A tal fin se toman como referencia los más recientes documentos jurídicos y políticos que se han promulgado en el país. Las ideas que se enuncian tienen su base en políticas que están directa o indirectamente enfocadas al sector en cuestión. Ellas son el punto de partida, dado que indican los derroteros a seguir para su continuidad a futuro dentro de los marcos de la dinámica de desarrollo que se proyecta en el país. Así pues, se valora el impacto que estas transformaciones puedan suscitar en un corto plazo para el cooperativismo cubano.

Palabras clave: cooperativas, perspectivas y regulación jurídica.

Abstract: This paper intends to analyze some of the institutional and practical perspectives that are opened for cooperatives in Cuba in the current constitutional and legal scenario. To this end, the most recent legal and political documents that have been promulgated in the country are taken as a reference. The ideas that are enunciated are based on policies that are directly or indirectly focused on the sector in question. They are the starting point, given that they indicate the paths to be followed for future continuity within the framework of the development dynamics that are projected in the country. Thus, the impact that these transformations may cause in the short term for Cuban cooperativism is valued.

Keywords: cooperatives, perspectives and legal regulation.

1 Doctora en Ciencias Jurídicas. Profesora Titular del Departamento de Derecho de la Universidad de Pinar del Río, Cuba. E-mail: oriselha@upr.edu.cu 


\section{Introducción}

El sector cooperativo en Cuba muestra dos grandes vertientes: la agraria y la no agropecuaria. La primera cuenta con más tiempo de existencia y mayor número de organizaciones asociadas, en tanto la segunda se distingue por su juventud y las expectativas que ha generado.

A pesar de sus diferencias, ambas tipologías se han visto involucradas en el proceso de perfeccionamiento institucional que se desarrolla en la isla ${ }^{2}$, que contempla a la utilización de la cooperativa como parte del modelo económico a potenciar. Como consecuencia de ello se ha progresado en la superación de algunas de las limitaciones de su ámbito jurídico-institucional ${ }^{3}$. En tal sentido se debe destacar que la Constitución de la República de Cuba de 2019 rebasa la concepción agropecuaria que primaba en el anterior texto y que se han dado los primeros pasos para una legislación unificadora y armonizadora del sector, con la promulgación de un solo cuerpo de normas para las de carácter agrario 4 .

No obstante lo antes apuntado, subsisten algunas importantes carencias ${ }^{5}$ que son ya conocidas: la ausencia de un ente público encargado de rectorar, diseñar e impulsar la política de atención al movi-

2 Al cual sirven de guía los Lineamientos de la Política Económica y Social del Partido y la Revolución (Vid.VI Congreso del PARTIDo Comunista de CuBA: Lineamientos de la Política Económica y Social del Partido y la Revolución, consultado en http://www. prensa-latina.cu/Dossiers/LineamientosVICongresoPCC.pdf, en fecha 1 de julio de 2012. (En lo adelante "Lineamientos») y VII CONGRESO DEL PARTIDO COMUNISTA DE CUBA Y ASAMblea Nacional del Poder Popular: Actualización de los Lineamientos de la Política Económica y Social del Partido y la Revolución para el periodo 2016-2021, consultado en http://www.cubadebate.cu/wp-content/uploads/2016/09/aqu\%C3\%AD.pdf, en fecha 20 de septiembre de 2016. (En lo adelante «Actualización de los Lineamientos»)), la Conceptualización del Modelo Económico y Social Cubano de Desarrollo Socialista (Vid. VII Congreso del Partido Comunista de Cuba: Conceptualización del Modelo Económico y Social Cubano de Desarrollo Socialista, publicación en forma de tabloide, 2016) y el Plan nacional de desarrollo económico y social hasta 2030: propuesta de visión de la nación, ejes y sectores estratégicos (Vid.VII Congreso del PARTIDo Comunista DE CubA: Plan nacional de desarrollo económico y social hasta 2030: propuesta de visión de la nación, ejes y sectores estratégicos, publicación en forma de tabloide, 2016).

3 Cfr. Rivera Gort, J.J y Rodríguez Musa, O.: «Historia y realidad jurídica de la cooperativa en Cuba. Aproximación desde la experiencia práctica a las noveles cooperativas no agropecuarias en Pinar del Río», en Boletín de la Asociación Internacional de Derecho Cooperativo, Núm. 49/2015, Bilbao, págs. 195-222.

4 Vid. Decreto-Ley No. 365/2018 «De las Cooperativas Agropecuarias» y Decreto No. 354/2018 Reglamento del Decreto-Ley De las Cooperativas Agropecuarias en la Gaceta Oficial No. 37 Ordinaria de 24 de mayo de 2019.

5 Vid. Rodríguez Musa, O.: La constitucionalización de la cooperativa. Una propuesta para su redimensionamiento en Cuba. Brasilia-DF: EditorialVincere Asociados. Coletânea IBECOOP, No. 1, 2017. 
miento, el constreñimiento legal —en general — a la modalidad de cooperativas de trabajo, la pervivencia del carácter «experimental» de las regulaciones de las entidades no agropecuarias ${ }^{6}$ y la insuficiente cultura jurídico-cooperativa.

Sobre estas bases puede sostenerse que, amén de sus diferencias, las dos manifestaciones del cooperativismo cubano tienen puntos relevantes en común. Ellos constituyen el presupuesto de partida para valorar las proyecciones inmediatas de este sector dentro del nuevo contexto de transformaciones asociado al desarrollo de los preceptos constitucionales y la implementación de las políticas públicas que se han priorizado en la primera etapa del Plan Nacional de Desarrollo Económico y Social hasta 2030.

Por tanto, el presente trabajo se propone analizar algunas de las perspectivas institucionales y prácticas que se abren para las cooperativas en Cuba en el actual escenario jurídico-político. A tal fin se tomarán como referencia los más recientes documentos legales que se han promulgado en el país, aludan estos o no directamente al sector en cuestión, siempre que indiquen una pauta de continuidad a futuro dentro de los marcos de la dinámica de desarrollo que se proyecta.

\section{Las cooperativas como protagonistas del desarrollo local}

En Cuba, la realidad institucional no ha permitido hasta la fecha que el movimiento cooperativo despliegue todas sus potencialidades en pos del desarrollo local. Las primeras menciones legislativas al respecto se encuentran en las normas coloniales, manteniendo desde entonces su presencia en el ordenamiento jurídico patrio, incluso, desde 1940 con rango constitucional. Sin embargo, esto no es suficiente para que pueda hablarse de una evolución de la dimensión jurídica de la ins-

6 En las normas publicadas en 2012 se atribuía a las mismas carácter experimental dada la novedad de su introducción en el país. Sin embargo, pasados seis años de experiencias al respecto, las disposiciones emitidas en 2019 mantienen dicho carácter. Al respecto de las opiniones suscitadas al respecto véanse los comentarios en Autoridades explican nuevas medidas respecto a cooperativas no agropecuarias, consultado en http://www.cubadebate.cu/noticias/2017/08/09/autoridades-explicannuevas-medidas-respecto-a-cooperativas-no-agropecuarias/\#.XcbID_S23IU, En vigor nuevas normas jurídicas sobre Cooperativas No Agropecuarias, consultado en http:// www.cubadebate.cu/noticias/2019/10/29/en-vigor-nuevas-normas-juridicas-sobrecooperativas-no-agropecuarias/\#.XcbH6vS23IU, y Nuevas normas jurídicas para las cooperativas no agropecuarias en Cuba, consultado en http://www.cubadebate.cu/ noticias/2019/08/30/nuevas-normas-juridicas-para-las-cooperativas-no-agropecuariasen-cuba/\#.XcbHsfS23IU, todo en fecha 8 de noviembre de 2019. 
titución en el país, en tanto su tracto histórico más de una vez ha estado marcado por el reduccionismo, las distorsiones y las omisiones ${ }^{7}$.

La situación descrita está llamada una transformación profunda al amparo de la Constitución aprobada en 2019. Según el Artículo 168, los municipios asumen como parte de sus responsabilidades «la satisfacción de las necesidades locales» y el «desarrollo económico y social de su territorio». Para ello están investidos de autonomía, tanto para decidir sobre la utilización de sus recursos y el ejercicio de las competencias que le corresponden, así como para dictar acuerdos y disposiciones normativas necesarias para el ejercicio de sus facultades, según lo dispuesto en la Constitución y las leyes (Artículo 169).

El reconocimiento de la autonomía y su extensión hasta la atribución del rol de gestor del desarrollo local a las municipalidades produce un relevante impacto en la política de desarrollo. Ello implica que los actores que interactúan en la localidad tendrán un peso relativo importante a la hora de conformar e implementar dicha política. Por tanto, el nuevo enfoque debe partir de utilizar los recursos endógenos y la atracción de inversiones externas.

Esta situación revaloriza a las cooperativas como actores a los que deberán recurrir las autoridades locales, toda vez que poseen un gran potencial por desplegar y son el único sujeto de emprendimiento empresarial colectivo para nacionales reconocido por la nueva Carta Magna en el marco legal vigente. Véase que el Artículo 22, en su inciso b), alude a la cooperativa como aquella forma de propiedad «sustentada en el trabajo colectivo de sus socios propietarios y en el ejercicio efectivo de los principios del cooperativismo».

Ante el escenario descrito conviene precisar entonces un conjunto de ideas que fungen como rectoras de la tesis que aquí se preconiza: (1) la actual Constitución cubana ha apostado por el reforzamiento de los municipios, en detrimento de la provincia; (2) por tanto, la responsabilidad de gestionar el desarrollo local es de la municipalidad; (3) ese desarrollo local es, además de económico y social, sostenible; (4) aun cuando no existan las normas complementarias, por medio de la aplicación directa constitucional, los entes locales poseen vías para instrumentar sus políticas de desarrollo; y (5) las cooperativas son un importante agente que las autoridades están obligados a incorporar en las mismas. Seguidamente se comentan las razones que sustentan esta afirmación.

7 Rodríguez Musa, O.: «Eficiencia socioeconómica de la gestión de las cooperativas no agropecuarias en Cuba», en Estudio sistemático del principio cooperativo de gestión democrática : su aplicación práctica en un modelo de empresa eficiente, Dykinson, Deusto, 2018, p. 137. 
Desde la propia determinación que se hace de la provincia en el Artículo 167 se deja sentado que esta constituye solo un «nivel intermedio entre las estructuras centrales del Estado y los municipios». De ahí que la función principal del Gobierno Provincial sea actuar «como coordinador entre las estructuras centrales del Estado y los municipios», armonizando sus intereses (Artículo 171).

En contraste, el Artículo 168, reivindica el rol de los municipios como «la unidad política-administrativa primaria y fundamental de la organización nacional» 8 . Su autonomía y responsabilidad en «la satisfacción de las necesidades locales» y el «desarrollo económico y social de su territorio» son, en consecuencia, lógicas derivaciones de tal concepción. Para materializar dicha autonomía se les reconoce la posibilidad recurrir a los principios de solidaridad, coordinación y colaboración (Artículo 169), con lo cual se constituyen en epicentro y protagonistas de las políticas locales.

Aunque a lo largo del Título VII «Organización Territorial del Estado» se reitera el sintagma nominal «desarrollo económico y social», la sistemática constitucional permite afirmar que ese desarrollo es, forzosamente, un desarrollo sostenible. A ello conduce el dictado del Artículo 75 que dispone el derecho de todas las personas a disfrutar de un medio ambiente sano y equilibrado, lo cual — como el resto del texto- las instituciones estatales están obligadas a respetar. Además, en el mismo precepto se formula el reconociendo a la estrecha vinculación existente entre «el desarrollo sostenible de la economía y la sociedad» como presupuesto indispensable «para hacer más racional la vida humana y asegurar la supervivencia, el bienestar y la seguridad de las generaciones actuales y futuras».

En cuanto al lugar protagónico que ha de atribuirse por las autoridades a las cooperativas conviene partir del modelo de Estado que se

8 En este sentido del reforzamiento del rol local se evidencian algunos avances y también contradicciones en las normas dictadas hasta la fecha.

Por ejemplo, en el nuevo paquete normativo (Vid. Decreto-Ley No. 366 «De las Cooperativas no Agropecuarias» y Decreto No. 356 «Reglamento de las Cooperativas no Agropecuarias», en Gaceta Oficial No. 63 Ordinaria de 30 de agosto de 2019) que dispone el funcionamiento de las cooperativas no agropecuarias (CNA) se continúan dando facultades al Consejo de la Administración Provincial, un órgano que existe en el sistema del Poder Popular según la nueva Constitución.

Sin embargo, en las más recientes normas que ordenan el trabajo por cuenta propia (Resolución No. 427/2019 del Ministerio de Finanzas y Precios) se faculta «a los consejos de la Administración municipales para regular los precios y tarifas fijos o máximos sobre los productos y servicios que prestan los trabajadores por cuenta propia cuando las circunstancias lo aconsejen y teniendo en cuenta las condiciones características de cada municipio», Siendo excepcionales las posibilidades de intervención otros niveles administrativos en tales asuntos. 
refrenda constitucionalmente. Se trata de «un Estado socialista de derecho y justicia social, democrático, independiente y soberano, organizado con todos y para el bien de todos como república unitaria e indivisible, fundada en el trabajo, la dignidad, el humanismo y la ética de sus ciudadanos para el disfrute de la libertad, la equidad, la igualdad, la solidaridad, el bienestar y la prosperidad individual y colectiva» (Artículo 1).

Como Estado socialista, guiado por el pensamiento marxista9 ${ }^{9}$ al cubano le corresponde estimular, con preferencia, las formas de producción y apropiación colectivas. En tal sentido dispone de dos posibilidades: la propiedad socialista de todo el pueblo (Artículo 22 a)) y la propiedad cooperativa. Esta última tiene una más inmediata posibilidad de socialización puesto que se sustenta en el trabajo colectivo de los socios-propietarios y cuenta para desenvolvimiento con el respaldo de los «principios del cooperativismo» (Artículo 22 b)) que conectan directamente con la axiología democrática, de equidad en la distribución y socialmente responsable que propugna el modelo social asumido ${ }^{10}$. Por ende, se refuerza doblemente la obligatoriedad de los entes locales de incluir en sus programas de desarrollo a las cooperativas, a fin de que estas desplieguen todo su potencial.

Todo lo anterior es posible, y obligatorio, por su carácter de mandato constitucional ${ }^{11}$ aun ante la ausencia de norma ordinaria que

9 Cfr. Preámbulo, Constitución De La República de Cuba, en Gaceta Oficial No. 5 Extraordinaria de 10 de abril de 2019.

10 Cfr. Declaración sobre la Identidad Cooperativa, consultado en El Hogar Obrero: Cooperativa de Consumo, Edificación y Crédito Ltda, en http://www.elhogarobrero1905.org.ar, en diciembre de 2009,

11 Al asumir este tratamiento la Constitución supera su carácter de programa político o de norma de mínimos, alcanzando entidad de verdadera norma jurídica. La primera consecuencia que esto trae aparejada es que "sus disposiciones no necesitan de mediación alguna para ser aplicadas, ni si quiera cuando el mismo poder constituyente haya impuesto la necesidad de dicha mediación vía desarrollo legislativo» (MEDINACELI RojAs, G.: La aplicación directa de la Constitución, Serie Magíster Universidad Andina Simón Bolívar, Sede Ecuador, Corporación Editora Nacional, Quito, 2013, p. 26).

El amparo para exigir esta conducta por lo implicados está en su esencia en el citado artículo 7 que tiene rango de principio fundamental (Capítulo I) dentro de los fundamentos políticos del orden constitucional (Título I).

Una segunda consecuencia es «la posibilidad de tutela judicial en caso de que alguna norma infraconstitucional o acto jurídico estatal o privado pretenda contradecirla» (Medinacel Rojas, G.: ob. cit., p. 26). Es decir, la carta magna deviene norma obligatoria tanto para los jueces, como para los funcionarios del Estado y los ciudadanos, quienes deben respetarla y aplicarla según corresponda (GUASTINI, R.: "La constitucionalización del ordenamiento jurídico: el caso italiano», en CARBOnelL, M. (comp.), Neoconstitucionalismo(s), Madrid, Trotta, 2003, p. 55-56). 
complemente lo establecido. El vacío que se presenta en esta temática deberá ser integrado sobre la base de las reglas del sistema ${ }^{12}$, asumiendo que este requiere de una solución jurídica que puede ser proporcionada en el proceso de aplicación del Derecho.

En virtud de la aplicabilidad directa de los preceptos de la ley suprema ${ }^{13}$, los municipios - haciendo uso de su autonomía- pueden y deben recurrir a su atribución de dictar acuerdos y disposiciones normativas necesarias para el ejercicio de sus facultades, según lo dispuesto en la Constitución y las leyes (Artículo 169). De esta manera estarían en condiciones de - dentro del orden constitucional- decidir sobre la utilización de sus recursos y dar el contenido y alcance que determinen a su política de desarrollo.

De darse la inacción de las autoridades locales o la preterición o discriminación de algún actor en su política —como pudiera ser el caso de las cooperativas-, esta sería susceptible de reclamación por contravenir los dictados de la Carta Magna. Este asunto, siendo de sede municipal, ostenta el amparo del amplio catálogo de garantías que se ofrece con los derechos de participación y petición a este nivel ${ }^{14}$. En el

12 Balaguer Callejón, F.: Fuentes del derecho. Principios del ordenamiento constitucional, Madrid, Tecnos, 1991, p. 164.

13 Además, debe considerarse que el articulado del texto cubano de 2019 conserva las directrices de control que, en cuando las normas, han ordenado al sistema de órganos estatales del país, según el cual se dispone que los superiores velen por que en el actuar, sus subordinados, no contravengan la Constitución y la legalidad (Cfr. Artículos 108 e) y g); 122 h) y j); 179 i) y j); y 191 I)). A ello se suma la introducción de la tutela de los derechos por medio de un procedimiento preferente, expedito y concentrado (Cfr. Artículo 92 en relación con el Artículo 99).

14 Artículo 200.La Asamblea Municipal del Poder Popular, a los efectos de garantizar los derechos de petición y de participación ciudadana:

a) convoca a consulta popular asuntos de interés local en correspondencia con sus atribuciones;

b) garantiza la correcta atención a los planteamientos, quejas y peticiones de la población;

c) garantiza el derecho de la población del municipio a proponerle el análisis de temas de su competencia;

d) mantiene un adecuado nivel de información a la población sobre las decisiones de interés general que se adoptan por los órganos del Poder Popular;

e) analiza, a petición de los ciudadanos, los acuerdos y disposiciones propias o de autoridades municipales subordinadas, por estimar aquellos que estos lesionan sus intereses, tanto individuales como colectivos, y adopta las medidas que correspondan; $y$

f) ejecuta, en el marco de su competencia, cualquier otra acción que resulte necesaria a fin de garantizar estos derechos.

La ley establece la forma y el ejercicio de estas garantías. 
supuesto de que la abstención u olvido configurara una conducta lesiva a un derecho sería posible, además, reclamar por vía judicial en los términos descritos por los artículos 92 y 99 .

\section{Informatización de las cooperativas como parte de la sociedad cubana}

Al calor de las dinámicas de modernización que imperan en el país el Ministerio de Comunicaciones aprobó la «Política Integral para el Perfeccionamiento de la Informatización de la Sociedad en Cuba» ${ }^{15}$ en 2017. Esta obedece al cumplimiento del Lineamiento $108-\mathrm{y}$ además de manera complementaria, a los 68, 69, 112, 119, 186, 209, 243 y 271-; al Capítulo 1, numeral 1.2.3. Perfeccionamiento del Estado Socialista, sus sistemas y órganos de dirección del Proyecto de Conceptualización del Modelo Económico y Social Cubano de Desarrollo Socialista ${ }^{16}$; y al Eje Estratégico Infraestructura del Proyecto de Plan Nacional de Desarrollo Económico y Social hasta el 203017.

Dentro de las previsiones de dicha política figura «Reordenar la actividad productiva y de servicios asociada al sector» para lo cual incluye «posibilitar la participación en el proceso de informatización de la sociedad de las formas no estatales de gestión», por lo que se entienden incluidas las cooperativas.

En cumplimiento de esa proyección de informatizar a la sociedad cubana se pusieron en vigor un grupo de normas publicadas en la Gaceta Oficial No. 45 Ordinaria de 4 de julio de 2019 de las cuales se puede colegir el alcance que en un breve lapso de tiempo debe derivarse de tal ambición.

15 Consultado en http://www.cubahora.cu/uploads/documento/2018/05/25/politicaintegral-para-el-perfeccionamiento-de-la-informatizacion-de-la-sociedad-en-cuba-0-0. pdf, en fecha 1 de noviembre de 2019.

16 «Están desarrolladas las tecnologías de la información, las comunicaciones y la automatización, de modo que contribuyen a una activa participación ciudadana — sobre todo de los jóvenes-; a la elevación del conocimiento, el nivel y calidad de vida; a la innovación, al perfeccionamiento del Estado, al desempeño de la economía nacional y de la esfera social».

17 En el mismo se apunta en su objetivo específico n. ${ }^{\circ}$ 8: «Desarrollar y sostener la infraestructura de las telecomunicaciones para lograr acceso universal y uso productivo de las tecnologías de la información y las comunicaciones (TIC) a partir del desarrollo de inversiones en tecnologías de avanzada a nivel internacional, que tecnologías de la información y las comunicaciones (TIC) a partir del desarrollo de inversiones en tecnologías de avanzada a nivel internacional, que permitan un mayor acceso a la banda ancha». 
En el Decreto-Ley No. 370/2018 «Sobre la Informatización de la Sociedad en Cuba» se reconoce que entre sus objetivos contempla favorecer el uso de las TIC en un conjunto de organizaciones que incluye a las cooperativas (Artículo 5 inciso g)). Para ello prescribe las líneas generales de obligado acatamiento por todos los sujetos dentro de las cuales les corresponde instrumentar el proceso de informatización en su esfera de actividades e implementar el control y fiscalización que corresponda (Artículo 62).

Este nivel de autonomía dejado a la gestión de la informatización puede revertirse en un corto plazo en una potencialidad para instrumentar la digitalización del sector cooperativo. Como punto de partida cabría considerar la utilización de la intermediación laboral o del mercado en línea, pasos previos y necesarios para evolucionar hacia el asiento de un nicho de cooperativismo de plataforma ${ }^{18}$.

La primera de estas alternativas resulta viable de inmediato, si se toma en consideración que en la reciente coyuntura energética vivida entre septiembre y octubre de 2019 se abogó por el teletrabajo ${ }^{19}$ como una variante admisible dentro de la libertad de formas pactadas de acuerdo con el Articulo $20^{20}$ de la Ley No. 116 «Código de Trabajo». Las restantes, dependerán en buena medida de los soportes tecnológicos que se introduzcan y generalicen en el país y el paulatino nivel de acceso a los mismos que tengan las entidades cooperativas, asunto este muy vinculado a disposiciones que se comentan infra.

Por su parte el Decreto No. 359/2019 «Sobre el Desarrollo de la Industria Cubana de Programas y Aplicaciones Informáticas» parte de sentar que las disposiciones contenidas en dicha norma resultan aplicables a las relaciones jurídicas que se establecen entre las distintas entidades cuyo objeto social o actividad comprenda el desarrollo de programas y aplicaciones informáticas y la prestación de servicios in-

18 Vid. Morales Gaitán, K. (coord..): La Disrupción Cooperativista. Reflexiones sobre cooperativismo en la era digital, 1ra Edición. Año Dual Alemania-México 2016-2017 y OuiShare México, 2017. pp. 88.

19 LABACENA Romero, Y.: «La opción del teletrabajo en Cuba debe ser perdurable», en Juventud Rebelde, publicado en http://www.juventudrebelde.cu/cuba/2019-09-21/ trabajando-en-casa, en fecha 21 septiembre 2019.

20 «La relación de trabajo se formaliza con el contrato del que son partes el trabajador y el empleador; mediante el cual, la persona contratada se compromete a ejecutar con eficiencia una labor, a observar las normas de disciplina y las demás que se acuerden, asimismo quien le emplea se obliga a pagarle una remuneración y a garantizarle las condiciones y derechos de trabajo y seguridad social que establece la legislación. Es nula cualquier cláusula contractual violatoria de la ley». Ley No. 116 «Código de Trabajo», en Gaceta Oficial No. 29 Extraordinaria de 17 de junio de 2014. 
formáticos asociados a esta industria (Artículo 3). Lo antes expuesto se complementa con el reconocimiento del objetivo de promover la vinculación de la empresa estatal socialista y los demás sujetos económicos no estatales en esta industria (Artículo 4) y del principio de la Industria cubana de programas y aplicaciones informáticas de exportación de productos y servicios, con participación de todas las formas de propiedad y gestión existentes en el modelo económico cubano (Artículo 7).

En consecuencia, se encarga al Ministerio de Comunicaciones trabajar para identificar, evaluar y proponer políticas y estrategias para la organización de la Industria de programas y aplicaciones, fomentando el desarrollo de la empresa estatal, de conjunto con los otros actores mencionados, para contribuir al desarrollo de la informatización de la sociedad y a sus exportaciones. Con tal propósito se deberá regular la participación de las formas de propiedad y de gestión no estatal en el desarrollo de aplicaciones y servicios informáticos (Artículo 11).

La trascendencia de estas disposiciones para el sector cooperativo puede sistematizarse en dos líneas fundamentales: en primer término, su reconocimiento como un agente a considerar dentro de un sector estratégico del desarrollo del país y, en segundo lugar, como un campo para la ampliación y diversificación de su actividad productiva, que puede alcanzar relevancia dentro y fuera del país.

En el empeño de viabilizar la utilización de las TIC en el desarrollo del país las disposiciones del Decreto No. 360/2019 «Sobre la Seguridad de las Tecnologías de la Información y la Comunicación y la Defensa del Ciberespacio Nacional» contemplan en el Artículo 26 que el Ministerio de Comunicaciones es el responsable de facilitar el hospedaje de los servicios de las entidades estatales y del sector no estatal en los centros de datos públicos para garantizar la racionalidad de las infraestructuras de seguridad y su despliegue y minimizar su diseminación. A esto se integra la Estrategia de Desarrollo de la Infraestructura de Banda Ancha en Cuba incluida en el Acuerdo No. 8611/2019, que asume la finalidad de maximizar el impacto de las telecomunicaciones y las tecnologías de la información y la comunicación en la transformación y modernización de la economía y la sociedad cubana, así como en la Seguridad y Defensa Nacional, mediante el empleo eficaz e intensivo de las nuevas tecnologías en correspondencia con la disponibilidad financiera del país.

Las dos normas recién citadas constituyen la apuesta por el establecimiento de las garantías materiales que viabilicen que las proyecciones previamente analizadas pueden llegar a materializarse. Como es lógico, en este camino se requerirá no solo del empeño y el esfuerzo humano, sino de una importante asignación patrimonial que respalden las pre- 
tensiones aludidas en términos de infraestructura. Los retos más evidentes que se aprecian en tal sentido para las cooperativas radicarían en tener una suficiente disposición de recursos para adquirir los soportes tecnológicos necesarios y en capacitar a los socios involucrados en el desarrollo de las actividades a informatizar. Al respecto, en principio, valdría la pena proyectar una gestión económica que potencie los fondos que deben cubrir tales gastos en dichas entidades.

\section{Retos para las cooperativas ante los nuevos escenarios del comercio}

La informatización, como fenómeno integral tiene incidencia en casi todos los aspectos de la vida social. Por ende, hay una estrecha relación entre lo comentado en el apartado anterior y dos de las más inminentes perspectivas de desarrollo del comercio en el país: comercialización de programas y aplicaciones informáticas e implementación del comercio electrónico.

El ya referido Decreto No. 359/2019 «Sobre el Desarrollo de la Industria Cubana de Programas y Aplicaciones Informáticas» responsabiliza al Ministerio del Comercio Exterior y la Inversión Extranjera con la promoción de la inversión extranjera y otras formas de asociación, para contribuir al crecimiento de las exportaciones y al progreso de la Industria; el establecimiento e implementación de normas que regulen la importación de productos y servicios informáticos en correspondencia con las necesidades del país; y la implementación de programas de exportación de servicios profesionales especializados en tecnología de la información y la comunicación e intensificar la cooperación internacional para el intercambio de expertos y la transferencia de tecnologías (Artículo 11). Todo ello, visto desde el conocimiento de que un actor asociado a la industria de programas y aplicaciones informáticas pueden ser las cooperativas, supone una puerta a la integración del sector con la actividad del comercio exterior.

A ello se debe sumar que en la Cartera de Oportunidades 2019$2020^{21}$ se señala como uno de sus principios generales para la inversión extranjera que esta "podrá dirigirse selectivamente al desarrollo de las formas de propiedad no estatal con personalidad jurídica, priorizán-

21 Ministerio del Comercio Exterior y la Inversión Extranjera (MINCEX): Cartera de Oportunidades de Inversión Extranjera 2019-2020, consultado http://www.procuba. cu/sites/default/files/carteraoportunidades/cartera_de_oportunidades_de_inversion_ extranjera_2019-2020_mincex.rar, en fecha 8 de noviembre de 2019. 
dose el sector cooperativo». Aunque seguidamente se limita a exponer las formas de llevar a cabo la «inversión extranjera con participación de cooperativas agropecuarias», soslayando a las formas no agropecuarias. Esta preterición no es comprensible en el marco constitucional de 2019 que no hace distinción alguna entre unas y otras, lo que conlleva a suponer que esta restricción será superada en la proyección siguiente.

Sobre ese particular, también puede apreciarse la evolución experimentada respecto a «la posibilidad de que las cooperativas, tanto las agropecuarias como las no agropecuarias, por su carácter de personas jurídicas, puedan ser consideradas como inversionistas nacionales» ${ }^{22}$. Se trata de diversificar las fuentes de financiamiento para el desarrollo interno del país, convirtiendo a todos los sujetos económicos en protagonistas del mismo y dando espacios para su desenvolvimiento y legitimación.

Estas oportunidades, de inserción interna y externa, en programas de inversión suponen un reto para las cooperativas, pues implican aumentar sus niveles de actividad y aprehender las herramientas esenciales para desenvolverse en un entramado de relaciones complejas por su dinámica. A ello habría que sumar la capacidad para determinar donde se encuentran esas áreas de expansión, pues no todas las normas de los distintos sectores productivos del país se han identificado con esta política de integración de sectores ${ }^{23}$.

También en la cuerda de la informatización es pertinente tratar la cuestión del comercio electrónico. No es un secreto que para un desempeño exitoso, ágil y atemperado a las exigencias del mundo moderno de las tareas comerciales a que se ven y, en un corto plazo, se verán abocadas las entidades cooperativas resulta esencial la correcta utilización de las potencialidades que ofrecen las TIC.

Según el ya citado Decreto-Ley No. 370/2018 en Cuba la actividad comercial soportada por la tecnología de la información y las comunicaciones comprende la promoción, la negociación de precios

22 Guía del Inversionista, consultado en http://www.granma.cu/file/sp/carterade-oportunidades-de-inversion-extranjera-23/datos/documentos/Cuba_guia-delinversionistaESP.pdf, en fecha 8 de noviembre de 2019.

23 En este sentido destaca la «territorialidad» impuesta con más claridad a las CNA de la construcción, de forma que no puedan operar fuera de la provincia donde está asentado su domicilio social.

Vid. Cooperativas de la construcción en Cuba: Cinco años después (+ Infografías), consultado en http://www.cubadebate.cu/especiales/2018/11/28/cooperativas-de-laconstruccion-en-cuba-cinco-anos-despues-infografias/\#.XcbKOvS23IU, en fecha 8 de noviembre de 2019. 
y condiciones de contratación, la facturación y el pago, entrega de bienes o servicios, así como servicios de posventa, entre otros (Artículo 38).

Las expectativas del país en tal sentido suponen que la implementación del comercio electrónico alcance a la exportación e importación de bienes y servicios (Artículo 39). Con tal finalidad se responsabiliza a los órganos y organismos estatales vinculados a esa actividad con la creación de las condiciones para su desarrollo y la capacitación de todos aquellos que se implicarán en el proceso de ejecución de la política trazada en tal sentido (Artículo 40).

Un rol determinante en la ejecución de lo previsto lo tiene el Banco Central de Cuba a quien se encarga autorizar los instrumentos de pago y sus proveedores de servicios, las infraestructuras y los mecanismos para el procesamiento de los pagos por vía electrónica (Artículo 44). También en el sentido de asegurar la tramitación de los negocios y dotarlos de seguridad, se promueve el empleo de certificados digitales de la Infraestructura Nacional de Llave Pública (Artículo 31).

Dada las particularidades de la temática, su novedad en la sociedad cubana y sus perspectivas de avance, es un desafío para las cooperativas sumarse a las iniciativas de capacitación y habilitarse las cuentas bancarias, las firmas electrónicas y demás instrumentos que se ponen a disposición de las personas jurídicas con el fin de llevar a vías de hecho la aspiración de generalizar el comercio por medio del uso de las TIC.

Una última cuestión, y no por ello menos relevante, es la asociada a las importaciones. Recientemente se adoptó una medida para facilitar la importación a solicitud del interesado, vía esta que estaba vedada con anterioridad, constituyendo un freno al desarrollo del sector no estatal de la economía que debía ceñirse a utilizar los suministros, insumos y maquinarias disponibles para ellos en el país.

En la Resolución No. 283/2019 del Ministerio del Comercio Exterior y la Inversión Extranjera publicada en la Gaceta Oficial No. 21 Extraordinaria de 16 de octubre de 2019 se disponen las regulaciones que rigen las relaciones comerciales en las operaciones de importación y la concertación de contratos de comisión para la venta de mercancías en consignación y en régimen de depósito de aduana, para la nomenclatura de productos que se autoricen a comercializar de forma minorista en moneda libremente convertible, entre las entidades importadoras relacionadas y las personas naturales.

A pesar del progreso que la norma representa, esta se limita a autorizar las importaciones respecto a una determinada "nomenclatura de productos» y solo para «personas naturales». En principio, 
respecto a la primera cuestión, se ha sostenido que «es una medida progresiva» 24 . En cuanto a la posibilidad de acceso a esta vía para las cooperativas, en tanto no se les facilite directamente, queda la posibilidad de que una persona importe un bien determinado para luego aportarlo al patrimonio común o que un representante realice el acto a título de mandatario de la persona jurídica ${ }^{25}$. Al respecto llama la atención que en la intervención pública del Ministro de Comercio Exterior y de la Inversión Extranjera se hizo referencia a que «las entidades importadoras acuerdan con las formas de gestión no estatal y las personas naturales los plazos requeridos para presentar las solicitudes de importación» ${ }^{26}$ cuando la norma no menciona a estos actores económicos.

Una complejidad añadida para las cooperativas en su posibilidad futura de acceder directamente a esta vía de importar productos, lo constituye la moneda en la que se han de efectuar los pagos. Las personas jurídicas nacionales hasta la fecha cuentan con cuentas en dos monedas nacionales de curso legal en el país el CUP y el CUC, sin embargo, las medidas recientemente anunciadas responden a la necesidad de captar divisas extranjeras, con lo cual se establece su uso solo por personas naturales en los términos dispuestos por el Banco Central27.

24 Vid. Autoridades cubanas responden inquietudes de la población sobre nuevas medidas económicas, consultado en http://www.cubadebate.cu/noticias/2019/10/16/ autoridades-cubanas-responden-inquietudes-de-la-poblacion-sobre-nuevas-medidaseconomicas/\#.XcWhz_S23IU, en fecha 20 de octubre de 2019.

25 Vid. Titulo XI «Mandato» del Libro Tercero «Derecho de Obligaciones y Contratos» de la Ley N. ${ }^{\circ} 59$ de 1987, Código Civil de la República de Cuba, Ministerio de Justicia, La Habana, 1998.

26 Cfr. Cuba: Autorizan venta en divisas convertibles en tiendas e importación de productos mediante empresas estatales (+ Video), consultado en http://www. cubadebate.cu/noticias/2019/10/15/gobierno-cubano-anuncia-nuevas-medidaseconomicas-video/\#.XbwVqPTB_IU, en fecha 30 de octubre de 2019.

27 «Las cuentas bancarias en dólares estadounidenses de las personas naturales reciben fondos mediante transferencias bancarias del exterior en cualquier moneda libremente convertible; de transferencias bancarias desde otras cuentas en moneda libremente convertible que operan en bancos cubanos; transferencias de FINCIMEX S.A. por concepto de remesas, y mediante depósitos en efectivo de dólares estadounidenses, euros, libras esterlinas, dólares canadienses, francos suizos, pesos mexicanos, coronas danesas, coronas noruegas, coronas suecas y yenes japoneses». Resolución No. 275/2019 del Banco Central de Cuba, en Gaceta Oficial No. 21 Extraordinaria de 16 de octubre de 2019. 


\section{Proyección de las cooperativas ante la expansión de la propiedad mixta}

Una de las diferencias más notables en la configuración del entramado de las relaciones económicas, erróneamente reducido a la denominación de «formas de propiedad» 28 , en la Constitución cubana de 2019 lo constituye la introducción con carácter propio de la propiedad mixta.

Se asumió como tal a «la formada por la combinación de dos o más formas de propiedad» 29 . En claro acatamiento de la Conceptualización del Modelo Económico y Social Cubano de Desarrollo Socialista se consagró esta combinación de otras formas preexistentes "constituidas entre entidades nacionales de diferentes formas de propiedad o con inversionistas extranjeros», cuya vigencia tiene la duración previamente acordada por las partes, las cuales actúan enmarcadas en normas de derecho de carácter privado.

La diferencia fundamental que dicho precepto marca con su predecesor radica en que la Constitución anterior solo reconocía la posibilidad de asociación económica en materia de inversión extranjera. Precisamente, por cuanto a la propiedad mixta se le amplía su alcance, al reconocer este derecho entre los diferentes actores económicos, se hace necesario que se promulguen disposiciones especiales ordenadoras de la misma en la variedad de combinaciones ahora posibles.

En tal sentido merece consideración el parecer de que se dé prioridad a aquellas variantes que ponderen el interés social o general. Para dar sustento a tal opinión es válido recordar que para MARX y ENGELS «la propiedad está presente, de manera directa o mediatizada, en cualquier acto o relación social, decidiendo, en última instancia, su carácter y tendencias» ${ }^{30}$. Luego, una sociedad socialista ha de ponderar las alianzas entre las formas de relacionarse en la producción que susten-

28 «para los fundadores del marxismo la propiedad no era una relación entre el hombre y los medios de producción sino una relación entre personas con motivo de la apropiación de estos medios y de los resultados de la producción». GARCía VALDÉs, C.M.: "La propiedad en la economía y en su modelo de funcionamiento. (Repasando la historia, la teoría y provocando el debate)», en Cuba Socialista, consultado en http:// www.cubasocialista.cu/2018/05/15/la-propiedad-en-la-economia-y-en-su-modelo-defuncionamiento-repasando-la-historia-la-teoria-y-provocando-el-debate/, en fecha 8 de noviembre de 2019.

29 Artículo 22, inciso e) Constitución de la República de Cuba, 2019.

30 García Valdés, C.M.: ob. cit. 
tan las características deseadas en sus relaciones sociales y, en última instancia, superestructurales ${ }^{31}$.

Al respecto BARRERA Rodríguez propone la alianza entre la empresa estatal y las cooperativas, pues articular estas formas de gestión y propiedad puede «implicar ventajas como el aumento de mercado para ambas, acceso a financiamiento por la unión de capitales, la recuperación de fuerza de trabajo calificada o el aprovechamiento de recursos que hoy se están quedando completamente en el sector privado»32.

Tal vez, esta llegue a convertirse en una alternativa en la superación del limitado papel que ha tenido, como regla, la propiedad cooperativa y su subordinación a la propiedad estatal en las economías socialistas en construcción ${ }^{33}$. A tales efectos es necesario una política pública de estímulo y atención a estas iniciativas — que por sus características pueden ser ignoradas por los entes rectores del sector estatal o del sector cooperativo, si lo hubiera, por considerarlas extrañas a sus funciones- que desde incentivos legales y económicos de diverso tipo respalde su desarrollo.

El cauce legal para tal propuesta cuenta con el mencionado respaldo de la Carta Magna y —a efectos prácticos - en tanto se promulgue una nueva disposición que ordene esta figura, podría materializarse por medio de la interpretación de sus postulados con las disposiciones mercantiles vigentes ${ }^{34}$, dando paso a un tipo societario de carácter nacional.

\section{Necesidad de perfeccionamiento de la asesoría jurídica a las cooperativas}

La novedad, dinámica y complejidad del panorama socioeconómico y legal expuesto hacen aconsejable revisar y perfeccionar las

31 La reflexión sobre las razones que hacen preeminente la pertinencia de regular las propiedades mixtas con presencia cooperativas obedece la alerta que despierta en los estudiosos del cooperativismo que la posibilidad de constituir cooperativas de segundo grado, que estaba presente en el primer paquete de disposiciones experimentales promulgado en 2012, fue excluida de las nuevas regulaciones del sector cooperativo no agropecuario.

32 Barrera Rodríguez, S.: «Empresa estatal-cooperativa: Interrogantes», en Rodríguez Musa, O. y Hernández Aguilar, O. (coordinadores), Apuntes de Derecho Cooperativo para Cuba, Ediciones Loynaz, Pinar del Río, 2018, pp. 210-227.

33 García Valdés, C.M.: ob. cit.

34 Nótese que la misma flexibilidad de las regulaciones mercantiles vigente permitió en su día la inclusión en tráfico jurídico de esta sede de las CNA luego de las publicaciones del primer grupo de normas experimentales en 2012. 
maneras en que se realiza el asesoramiento jurídico a las cooperativas. Al respecto en la actualidad se siguen las pautas de la Resolución No. 41/2018 que aprobó el «Reglamento para el ejercicio de la actividad de Asesoramiento Jurídico» ${ }^{35}$. No obstante, ya se ha dejado sentado $^{36}$ que la implementación de esta norma es susceptible de mejoras en el sentido de influir en que se ordene el actuar de las entidades existentes de forma coherente con su identidad y en congruencia con las proyecciones de desarrollo deseadas.

La relevancia de optimizar el asesoramiento jurídico obedece a que las acciones que el jurista/asesor/consultor realiza tienen reflejo directo en la forma en que se proyecta el ente cooperativo. Tómese en cuenta que este es el responsable de confeccionar o actualizar los documentos que constituyen la base legal de la entidad; orientar y/o responder consultas al representante legal y a otros directivos u órganos del sujeto asesorado; redactar instrumentos jurídicos y otros documentos; y representar legalmente a la organización ante el órgano jurisdiccional, registros y oficinas del Estado 37 .

Al contrastar los aspectos analizados a lo largo de este trabajo, se evidencia que las esferas de acción de las cooperativas presentan una clara perspectiva de aumento, con el consecuente incremento de las exigencias en el plano legal. La magnitud de esta cuestión reviste singularidades en el escenario cooperativo, toda vez que los decisores, entiéndase los socios y los representantes, deben estar debidamente informados al respecto de las particularidades propias de los actos a realizar a fin de determinar los causes que mejor se ajusten a sus expectativas. Por ende, la preparación y el actuar de los juristas que fungen como asesores tendrán que multiplicarse, rebasando notablemente los actuales límites.

Por tal motivo, el estudio para la reorganización del proceso de asesoramiento debe contar con referentes teóricos precisos, pero también prácticos, que permitan procurar una clara delimitación de las formas, alcances y contenidos que pueden asumir las intervenciones de las cooperativas en las distintas líneas estratégicas de desarrollo existentes. En particular, han de precisarse las acciones de asesoramiento que corres-

35 Gaceta Oficial No. 20 Extraordinaria de 5 de marzo de 2018.

36 Rodríguez Musa, O. y Hernández Aguilar, O.: La auto-regulación en las cooperativas no agropecuarias cubanas. Propuestas para su optimización mediante la asesoría jurídica, consultado en http://eventos.upr.edu.cu/index.php/MARDELTUR2019/TIESS/ paper/viewFile/2036/1370, en fecha 8 de noviembre de 2019

37 Universidad de Pinar del Río (UPR)-Empresa Provincial de Servicios Legales (EPSEL). Informe de Resultados parciales del Proyecto de Investigación «Metodología para perfeccionar el proceso de asesoría jurídica a las Cooperativas no Agropecuarias de la provincia de Pinar del Río», a desarrollarse entre los años 2018 y 2022. Pinar del Rio, 2018. 
ponden en cada caso a fin de acceder a las vías legalmente disponibles en los distintos escenarios (V. gr.: Iniciativas Municipales de Desarrollo Local (IMDL), Proyectos de Colaboración Internacional, convocatorias de agencias internacionales, etc.), por medio de los instrumentos legales adecuados ( $V$. gr.: contratos, convenios, etc.), de forma que sea posible explotar al máximo la capacidad de estas organizaciones en favor de la localidad y el país e integrarse propositiva y activamente a la política de desarrollo.

En este empeño los asesores/consultores no se encuentran solos. La idea de potenciar la labor de acompañamiento legal al sector en cuestión ha encontrado una acogida favorable en la Universidad de Pinar del Río, puesto que la misma ha mantenido por más de veinte años un compromiso académico he investigativo ascendente con la promoción de cooperativismo y el desarrollo local a través del Centro de Estudios de Desarrollo Cooperativo y Comunitario (CEDECOM), devenido en Centro de Estudios de Dirección, Desarrollo Local, Turismo y Cooperativismo (CE-GESTA). Además, esta línea de investigación está integrada al Proyecto de I+D+i (PI-175) «Metodología para perfeccionar el proceso de asesoría jurídica de las Cooperativas No Agropecuarias en la provincia de Pinar del Río, desde su gestación hasta su disolución», que actualmente se encuentra en ejecución.

A ello se ha unido el interés que ha ganado entre los juristas la temática, como lo demuestra la acogida que han tenido las dos ediciones del Taller Internacional de Derecho Cooperativo (COODER). En este evento se ha manifestado un consenso en torno a la idea de que «la capacidad de autorregulación de las cooperativas, unido a una labor de asesoría jurídica de calidad, tienen potencialidades para superar la mayor parte de las limitaciones que hoy presentan las experiencias prácticas relativas a estas formas asociativas en Cuba» ${ }^{38}$. Sobre tal base es posible sostener que corresponde, igualmente, un rol de peso a dicha labor en los nuevos escenarios institucionales y prácticos que se abren al desenvolvimiento de las cooperativas cubanas.

\section{A modo de conclusiones}

En el actual escenario socioeconómico y jurídico del país se pueden vaticinar importantes perspectivas institucionales y prácticas para el de-

38 COODER: Relatoría del II Taller Internacional de Derecho Cooperativo. Universidad de Pinar del Río, 2018. 
senvolvimiento futuro de las cooperativas entre las que cabe considerar:

- Su vinculación, como agente activo, al modelo de desarrollo económico, social y sostenible, aprovechando el marco legal instrumentado por la Constitución de la República de 2019 que potencia a los municipios como responsables del mismo a nivel local.

- Su integración a la informatización de la sociedad cubana, aprovechando en su actividad las ventajas de la digitalización e incorporándose a la industria nacional del ramo. En ambos sentidos estas organizaciones deben llevar a cabo un ordenado programa de preparación en términos económicos y humanos que les permita una inserción exitosa en dicha política nacional.

- El aprovechamiento de los causes que, paulatinamente, ofrezca el MINCEX a la exportación de bienes y servicios, la vinculación a la inversión extranjera y la importación, complementando lo anterior con el adecuado manejo de las ventajas del comercio electrónico.

- La articulación con otras formas de propiedad y gestión en la denominada propiedad mixta, potenciando dentro de esa alianza la preeminencia de los valores del cooperativismo de que es portadora y que guardan una estrecha relación con las finalidades del sistema de relaciones que en Cuba se aspira a construir.

- El reordenamiento del asesoramiento jurídico que reciben las entidades del sector a tenor de las exigencias del contexto y revalorizando su relevancia dada su incidencia en la adecuada información que a de preceder a la toma de decisiones por parte de los socios.

\section{Bibliografía}

AIC: Declaración sobre la Identidad Cooperativa, consultado en El Hogar Obrero: Cooperativa de Consumo, Edificación y Crédito Ltda, en http:// www.elhogarobrero1905.org.ar, en diciembre de 2009.

Balaguer Callejón, F.: Fuentes del derecho. Principios del ordenamiento constitucional, Madrid, Tecnos, 1991.

Barrera Rodríguez, S.: «Empresa estatal-cooperativa: Interrogantes», en Rodríguez Musa, O. y HeRnández Aguilar, O. (coordinadores), Apuntes de Derecho Cooperativo para Cuba, Ediciones Loynaz, Pinar del Río, 2018, pp. 210-227.

COODER: Relatoría del II Taller Internacional de Derecho Cooperativo. Universidad de Pinar del Río, 2018. 
García VAldés, C.M.: «La propiedad en la economía y en su modelo de funcionamiento. (Repasando la historia, la teoría y provocando el debate)», en Cuba Socialista, consultado en http://www.cubasocialista.cu/2018/05/15/lapropiedad-en-la-economia-y-en-su-modelo-de-funcionamiento-repasandola-historia-la-teoria-y-provocando-el-debate/, en fecha 8 de noviembre de 2019.

GUASTINI, R.: «La constitucionalización del ordenamiento jurídico: el caso italiano», en Carbonell, M. (comp.), Neoconstitucionalismo(s), Madrid, Trotta, 2003.

LABACENA Romero, Y.: «La opción del teletrabajo en Cuba debe ser perdurable», en Juventud Rebelde, publicado en http://www.juventudrebelde.cu/ cuba/2019-09-21/trabajando-en-casa, en fecha 21 septiembre 2019.

Medinaceli Rojas, G.: La aplicación directa de la Constitución, Serie Magíster Universidad Andina Simón Bolívar, Sede Ecuador, Corporación Editora Nacional, Quito, 2013.

Ministerio del Comercio Exterior y la Inversión Extranjera (MinCEX): Cartera de Oportunidades de Inversión Extranjera 2019-2020, consultado http://www.procuba.cu/sites/default/files/carteraoportunidades/cartera_de_ oportunidades_de_inversion_extranjera_2019-2020_mincex.rar, en fecha 8 de noviembre de 2019.

MorAles GAITÁN, K. (coord.): La Disrupción Cooperativista. Reflexiones sobre cooperativismo en la era digital, 1. a edición. Año Dual Alemania-México 2016-2017 y OuiShare México, 2017. pp. 88.

Rivera Gort, J.J y Rodríguez MusA, O.: «Historia y realidad jurídica de la cooperativa en Cuba. Aproximación desde la experiencia práctica a las noveles cooperativas no agropecuarias en Pinar del Río», en Boletín de la Asociación Internacional de Derecho Cooperativo, Núm. 49/2015, Bilbao, págs. 195-222.

RodríGUEz MusA, O.: La constitucionalización de la cooperativa. Una propuesta para su redimensionamiento en Cuba. Brasilia-DF: Editorial Vincere Asociados. Coletânea IBECOOP, No. 1, 2017.

RodríGuez MuSA, O.: «Eficiencia socioeconómica de la gestión de las cooperativas no agropecuarias en Cuba», en Estudio sistemático del principio cooperativo de gestión democrática : su aplicación práctica en un modelo de empresa eficiente, Dykinson, Deusto, 2018.

Rodríguez Musa, O. y Hernández Aguilar, O.: La auto-regulación en las cooperativas no agropecuarias cubanas. Propuestas para su optimización mediante la asesoría jurídica, consultado en http://eventos.upr.edu.cu/index.php/ MARDELTUR2019/TIESS/paper/viewFile/2036/1370, en fecha 8 de noviembre de 2019.

Universidad de Pinar del Río (UPR)-Empresa Provincial de Servicios Legales (EPSEL). Informe de Resultados parciales del Proyecto de Investigación «Metodología para perfeccionar el proceso de asesoría jurídica a las Cooperativas no Agropecuarias de la provincia de Pinar del Río», a desarrollarse entre los años 2018 y 2022. Pinar del Río, 2018.

VI Congreso del Partido Comunista de Cuba: Lineamientos de la Política Económica y Social del Partido y la Revolución, consultado en http://www.prensa- 
latina.cu/Dossiers/LineamientosVICongresoPCC.pdf, en fecha 1 de julio de 2012.

VII Congreso del Partido Comunista de Cuba y Asamblea Nacional del Poder Popular: Actualización de los Lineamientos de la Política Económica y Social del Partido y la Revolución para el periodo 2016-2021, consultado en http://www.cubadebate.cu/wp-content/uploads/2016/09/aqu\%C3\%AD. pdf, en fecha 20 de septiembre de 2016.

VII Congreso del Partido Comunista de Cuba: Conceptualización del Modelo Económico y Social Cubano de Desarrollo Socialista, publicación en forma de tabloide, 2016.

VII Congreso del Partido Comunista de Cuba: Plan nacional de desarrollo económico y social hasta 2030: propuesta de visión de la nación, ejes y sectores estratégicos, publicación en forma de tabloide, 2016.

\section{Otros}

AUTORIDADES CUBANAS RESPONDEN INQUIETUDES DE LA POBLACIÓN SOBRE NUEVAS MEDIDAS ECONÓMICAS, consultado en http://www.cubadebate.cu/noticias/2019/10/16/ autoridades-cubanas-responden-inquietudes-de-la-poblacion-sobrenuevas-medidas-economicas/\#.XcWhz_S23IU, en fecha 20 de octubre de 2019.

AUTORIDADES EXPLICAN NUEVAS MEDIDAS RESPECTO A COOPERATIVAS NO AGROPECUARIAS, consultado en http://www.cubadebate.cu/noticias/2017/08/09/autoridades-explican-nuevas-medidas-respecto-a-cooperativas-no-agropecuarias/\#. XcbID_S23IU, en fecha 8 de noviembre de 2019.

COOPERATIVAS DE LA CONSTRUCCIÓN EN CUBA: CINCO AÑOS DESPUÉS (+ INFOGRAFÍAS), consultado en http://www.cubadebate.cu/especiales/2018/11/28/cooperativas-de-la-construccion-en-cuba-cinco-anos-despues-infografias/\#.XcbKOvS23IU, en fecha 8 de noviembre de 2019.

CUBA: AUTORIZAN VENTA EN DIVISAS CONVERTIBLES EN TIENDAS E IMPORTACIÓN DE PRODUCTOS MEDIANTE EMPRESAS ESTATALES (+ VIDEO), consultado en http://www.cubadebate.cu/noticias/2019/10/15/gobierno-cubano-anuncia-nuevas-medidaseconomicas-video/\#.XbwVqPTB_IU, en fecha 30 de octubre de 2019.

EN VIGOR NUEVAS NORMAS JURIIICAS SOBRE COOPERATIVAS NO AgROPECUARIAS, consultado en http://www.cubadebate.cu/noticias/2019/10/29/en-vigor-nuevasnormas-juridicas-sobre-cooperativas-no-agropecuarias/\#.XcbH6vS23IU, en fecha 8 de noviembre de 2019.

GUIAA DEL INVERSIONISTA, consultado en http://www.granma.cu/file/sp/cartera-deoportunidades-de-inversion-extranjera-23/datos/documentos/Cuba_guiadel-inversionistaESP.pdf, en fecha 8 de noviembre de 2019.

NUEVAS NORMAS JURIDICAS PARA LAS COOPERATIVAS NO AGROPECUARIAS EN CUBA, consultado en http://www.cubadebate.cu/noticias/2019/08/30/nuevas-normas-juridicas-para-las-cooperativas-no-agropecuarias-en-cuba/\#.XcbHsfS23IU, en fecha 8 de noviembre de 2019. 
Politica Integral para el Perfeccionamiento de la Informatización de la SoCIEDAD EN CUBA, consultado en http://www.cubahora.cu/uploads/ documento/2018/05/25/politica-integral-para-el-perfeccionamiento-de-lainformatizacion-de-la-sociedad-en-cuba-0-0.pdf, en fecha 1 de noviembre de 2019.

Leyes

Constitución de la República de Cuba, en Gaceta Oficial No. 5 Extraordinaria de 10 de abril de 2019.

Código Civil de la República de Cuba, Ministerio de Justicia, La Habana, 1998.

LEY No. 116. "Código de Trabajo», en Gaceta Oficial No. 29 Extraordinaria de 17 de junio de 2014

DeCReto-Ley No. 365/2018. «De las Cooperativas Agropecuarias» y Decreto No. 354/2018 Reglamento del Decreto-Ley De las Cooperativas Agropecuarias en Gaceta Oficial No. 37 Ordinaria de 24 de mayo de 2019.

DeCReto-Ley No. 366. «De las Cooperativas no Agropecuarias» y Decreto No. 356 «Reglamento de las Cooperativas no Agropecuarias», en Gaceta Oficial No. 63 Ordinaria de 30 de agosto de 2019.

RESOLUCIÓn No. 41/2018. "Reglamento para el ejercicio de la actividad de Asesoramiento Jurídico», en Gaceta Oficial No. 20 Extraordinaria de 5 de marzo de 2018.

Resolución No. 275/2019 del Banco Central de Cuba, en Gaceta Oficial No. 21 Extraordinaria de 16 de octubre de 2019.

Resolución No. 283/2019 del Ministerio del Comercio Exterior y la Inversión EXTRANJERA, en Gaceta Oficial No. 21 Extraordinaria de 16 de octubre de 2019.

Resolución No. 427/2019 del Ministerio de Finanzas y Precios, en Gaceta Oficial No. 85 Ordinaria de 6 de noviembre de 2019. 


\section{Derechos de autor}

http://dec.revistas.deusto.es/

La revista Deusto Estudios Cooperativos es una revista de acceso abierto lo que significa que es de libre acceso en su integridad inmediatamente después de la publicación de cada número. Se permite su lectura, la búsqueda, descarga, distribución y reutilización legal en cualquier tipo de soporte sólo para fines no comerciales y según lo previsto por la ley; sin la previa autorización de la Editorial (Universidad de Deusto) o el autor, siempre que la obra original sea debidamente citada (número, año, páginas y DOI si procede) y cualquier cambio en el original esté claramente indicado.

\section{Copyright}

The Deusto Journal of Cooperative Studies is an Open Access journal which means that it is free for full and immediate access, reading, search, download, distribution, and lawful reuse in any medium only for non-commercial purposes, without prior permission from the Publisher or the author; provided the original work is properly cited and any changes to the original are clearly indicated. 